\title{
O AVANÇO CONSERVADOR NA LEGISLAÇÃO BRASILEIRA E SEUS IMPACTOS NA EDUCAÇÃO
}

\author{
CONSERVATIVE ADVANCEMENT IN BRAZILIAN LEGISLATION AND ITS IMPACTS \\ ON EDUCATION
}

\author{
Simone de Fátima Flach ${ }^{1}$ \\ Universidade Estadual de Ponta Grossa (UEPG) \\ Karen Cristina Jensen Ruppel da Silva ${ }^{2}$ \\ Universidade Estadual de Ponta Grossa (UEPG)
}

\begin{abstract}
Resumo
Sob a luz do materialismo histórico e dialético, o presente texto analisa os impactos do conservadorismo em ascensão no Brasil em propostas e aprovações de alteração da legislação educacional brasileira. Para tanto, a partir de pesquisa bibliográfica e documental, este artigo apresenta algumas características do conservadorismo que fundamenta as ações sociais e políticas no Brasil; discute ações, projetos e leis de cunho conservador que pretendem alterar ou alteram a organização da oferta educacional no país. Por fim, aponta que o avanço conservador, evidenciado em propostas e aprovações de alteração da legislação, limita a formação dos estudantes e o trabalho dos professores, fatos que colaboram para uma sociedade desigual, preconceituosa e subserviente aos interesses dominantes.
\end{abstract}

Palavras-chave: Educação. Conservadorismo. Legislação Educacional. Formação de estudantes.

\begin{abstract}
In the light of the historical and dialectical materialism, this text analyzes the impacts of conservatism on the rise in Brazil in proposals and approvals for changes in Brazilian educational legislation. To do so, based on bibliographical and documentary research, this paper presents some characteristics of the conservatism that underpins the social and political actions in Brazil; discusses actions, projects and laws of a conservative nature that intend to alter or alter the organization of the educational offer in the country. Finally, it points out that the conservative advancement, evidenced in proposals and approvals of alteration of the legislation, limits the education of the students and the work of the teachers, facts that collaborate for an unequal society, prejudiced and subservient to the dominant interests.
\end{abstract}

Keywords: Education. Conservatism. Educational Legislation. Student education.

\footnotetext{
1 Doutora em Educação. Docente do Departamento de Educação e do Programa de Pós-Graduação em Educação da Universidade Estadual de Ponta Grossa - UEPG.

2 Mestre e Doutoranda em Educação pelo Programa de Pós-Graduação em Educação da Universidade Estadual de Ponta Grossa - UEPG.
}

Cadernos GPOSSHE On-line, Fortaleza, v. 2, n. 1, 2019. 


\section{Introdução}

De te fabula narratur! ${ }^{3}$ Karl Marx, 2002)

A expressão que dá início a discussão aqui proposta, retirada do prefácio da 1 a edição d’O Capital, pode ser considerada como um alerta de Karl Marx ao leitor alemão, em relação às as análises realizadas sobre o modo de produção capitalista mais avançado para a época, de modo a expressar que a realidade ali exposta dizia respeito a um conjunto muito maior que aquele restrito ao espaço europeu não continental e que "o país mais desenvolvido não faz mais do que representar a imagem futura do menos desenvolvido" (MARX, 2002, p. 16).

Com isso queremos alertar o leitor que as reflexões aqui expostas expressam o antagonismo social que rege a atual forma de sociabilidade e que, por vezes, são ignoradas por significativa parcela da população. Mais uma vez Marx (2002, p. 17) nos auxilia no argumento: "Perseu tinha um capacete que o tornava invisível para perseguir os monstros. Nós, de nossa parte, nos embuçamos com nosso capuz mágico, tapando nossos olhos e nossos ouvidos, para poder negar as monstruosidades existentes".

Com essas reflexões introdutórias e com o compromisso de desvelar os significados a respeito do pensamento conservador que se alastra e fortalece no seio social brasileiro, o presente texto tem por objetivo analisar os impactos do conservadorismo em propostas e aprovações da legislação educacional brasileira, as quais impactam sobremaneira na oferta da educação em escolas públicas, espaço privilegiado de formação da classe trabalhadora. Como não poderia deixar de ser, o referencial teórico-metodológico que dá sustentação aos argumentos e análises é o materialismo histórico e dialético, tal qual proposto por Marx e Engels e, posteriormente por Antonio Gramsci.

Para tanto, o texto apresenta: alguns fundamentos e características históricas do desenvolvimento do pensamento conservador e como esse se faz presente na realidade brasileira atual, principalmente nas ações sociais e políticas; os efeitos do movimento conservador nas propostas e alterações da legislação educacional e, por fim como essas questões impactam ou poderão impactar na oferta educacional brasileira, em especial na educação pública. Ao final indica o efeito limitador da perspectiva conservadora, tanto no processo formativo quanto no trabalho dos professores, visto que perpetua o antagonismo de classes e, consequentemente a exploração de uma classe sobre a outra.

${ }^{3}$ A história é a teu respeito!

Cadernos GPOSSHE On-line, Fortaleza, v. 2, n. 1, 2019. 
Parafraseando o fundador da filosofia da práxis, alertamos que Não é róseo o colorido que damos aos conservadores, visto que, sob a luz do materialismo histórico e dialético, representam relações de classe e interesses de classe ${ }^{4}$. Nesse sentido, excluímos "[...] a responsabilidade do indivíduo por relações, das quais ele continua sendo, socialmente criatura, por mais que, subjetivamente, se julgue acima delas" (MARX, 2002, p. 18).

O avanço conservador que se instala nos campos social, político e educacional brasileiro é consequência da ação ou inoperância de diversos setores da sociedade e como tal representa o resultado da correlação de forças entre grupos antagônicos e evidencia toda a força daqueles que, nesse momento histórico, detém a hegemonia, seja pela coerção ou pelo consenso.

\section{Conservadorismo: fundamentos e características}

Onde existe uma ordem, é mais difícil que se tome a decisão de substituí-la por uma nova ordem [...]. (GRAMSCI, 2004, p. 83)

A discussão a respeito do conservadorismo ${ }^{5}$ no contexto brasileiro requer um detour sobre sua origem, principais discussões, fundamentos e características para, ao final, apontar como exerce influência na vida material, em especial no campo da educação, abarcando o planejamento, a execução, o acompanhamento e a avaliação de políticas educacionais.

A expressão conservadorismo tem se tornado comum no contexto brasileiro. É situação corriqueira, principalmente em discussões de cunho religioso e político partidário, o emprego desse termo para designar indivíduos preocupados com a moral e os costumes cristãos. No entanto, a discussão e sua defesa no senso comum se torna misto de verdade e engano, visto que expressa de forma dogmática o pensamento de determinados grupos, sem que o contexto social contraditório seja considerado. Por isso, a compreensão radical a respeito do termo conservadorismo requer uma incursão que ultrapasse a superficialidade e evidencie seus reais significados.

\footnotetext{
${ }^{4}$ Marx expressa que "Não foi róseo o colorido que dei às figuras do capitalista e do proprietário de terras. Mas aqui, as pessoas só interessam na medida em que representam categorias econômicas, em que simbolizam relações de classe e interesses de classe" (MARX, 2002, p. 18).

${ }^{5}$ Há distinções entre o conservadorismo "clássico", cujas origens podem ser indicadas no final do século XVIII e o conservadorismo atual, também denominado de "neoconservadorismo", desenvolvido no século XX, tendo suas premissas apropriadas pelo fascismo e pelo nazismo. Hodiernamente, o conservadorismo orienta diferentes perspectivas sociais, políticas e econômicas em plano global. O texto procurará expressar suas distinções e semelhanças.
} 
Segundo Escorsim Netto (2011) o conservadorismo é uma expressão cultural complexa, que teve sua origem e desenvolvimento vinculado a diversas vertentes teóricas. Em face disso, o termo abarca multiplicidade de sentidos, sendo utilizado em diferentes contextos e como justificativa de posicionamentos controversos e antagônicos. Segundo a autora retro mencionada, o conservadorismo surgiu como resposta à Revolução Francesa, com o propósito de expressar interesses da nobreza e clero enquanto grupos sociais que detinham certos privilégios no Antigo Regime.

A obra Reflexões, datada de 1790, de autoria de Edmund Burke pode ser considerada como fundante do pensamento conservador, visto que nela há a defesa do ordenamento societário ao Antigo Regime. Apreensivo frente aos acontecimentos de caráter insurreto na França, Burke (2016) argumenta que:

[...] deveria me abster de felicitar a França por sua nova liberdade até que tivesse conhecimento de como esta liberdade se harmoniza com o governo, o governo, com o poder público, com a disciplina e a obediência dos exércitos, com o recolhimento e a boa distribuição dos impostos, com a moralidade e a religião, com a solidez da propriedade, com a paz e a ordem, com os usos civis e sociais. Todas essas coisas são (à sua maneira) bens, e se vierem a faltar, a liberdade deixa de ser um benefício e tem pouca chance de durar muito tempo (BURKE, 2016, p. 30).

O conservadorismo de Burke emerge como oposição à configuração da sociedade burguesa e sua hegemonia econômica, social, política e cultural, uma vez que os conservadores dessa esteira de pensamento defendiam a continuidade do desenvolvimento capitalista, porém, sem a ruptura com as instituições pré-capitalistas como família, Igreja e as hierarquias sociais. Tratava-se de um repúdio à forma de ação política mobilizadora das massas e de um desprezo às novas organizações que abalavam as instituições sociais tradicionais (ESCORSIM NETTO, 2011). Nesse sentido, o conservadorismo clássico expressava o desejo do capitalismo associado ao desprezo pela Modernidade.

No processo de transformação social e produtiva, o conservadorismo também se modifica. A defesa de ideais revolucionários e de princípios liberais que culminou com a derrota do antigo Regime pelos revolucionários franceses, fez emergir o pensamento conservador em prol da defesa de interesses da antiga classe dominante. Naquele momento inicial, o conservadorismo se pautava no ataque à burguesia e seus princípios, principalmente o de igualdade. Todavia, em face do desenvolvimento do modo de produção capitalista e de todo o aparato exploratório que o sustenta e, em consequência, da possibilidade insurreta da classe trabalhadora, o pensamento conservador também se tornou antiproletário. A experiência da Comuna de Paris entre 1870 - 1871 teve efeito 
contraditório, visto que ao mesmo tempo em que mostrou a capacidade revolucionária dos trabalhadores, possibilitou a aliança entre a nobreza ainda existente e a classe burguesa e, consequentemente, a consolidação da burguesia no poder. Esse acontecimento consolidou o pensamento conservador como enfrentamento a qualquer movimento revolucionário, em especial quando oriundo da classe trabalhadora.

Gramsci (2007) faz importante reflexão sobre esse período, demonstrando a vitalidade da burguesia:

De fato, só em 1870- 1871, com a tentativa da Comuna, esgotam-se historicamente todos os germes nascidos em 1789, ou seja, não só a nova classe que luta pelo poder derrota os representantes da velha sociedade que não quer confessar-se definitivamente superada, mas derrota também os novíssimos grupos que consideram já ultrapassada a nova estrutura surgida da transformação iniciada em 1789 e demonstra assim sua vitalidade tanto em relação ao velho como em relação ao novíssimo (GRAMSCI, 2007, p. 39).

O processo histórico demonstra que, a burguesia se perpetua no poder também por meio da perspectiva conservadora que assume em defesa e manutenção das instituições que criou no processo revolucionário. Nesse sentido, de revolucionária a classe assume postura conservadora. A defesa da ordem e de interesses burgueses contra uma possível ameaça proletária torna-se o cerne do conservadorismo (ESCORSIM NETTO, 2011).

Comte e Tocqueville, pensadores bastante distintos entre si, podem ser considerados como intelectuais que atuaram na transição do conservadorismo antiburguês para o conservadorismo antiproletário sob a perspectiva do controle e estabilidade social, enfatizando a defesa da ordem. O repúdio pela revolução fica evidente em Tocqueville quando aponta:

Acredito na existência de resistências honestas e rebeliões legítimas. Não afirmo, pois, de maneira absoluta, que os homens dos tempos democráticos jamais devem fazer revoluções; penso, porém, que têm razões para hesitar mais que todos os outros, antes de intentá-las, e que mais vale sofrer muitos incômodos do estado presente que recorrer a remédio tão perigoso (TOCQUEVILLE, 2010, p. 477).

O alerta de perigo em trocar o certo pelo incerto é uma das premissas do conservadorismo. Em contraposição a essa visão conservadora, Gramsci (2004) faz alusão ao senso comum "que prega habitualmente que é melhor um ovo hoje do que uma galinha amanhã" sendo que, necessariamente para ter a galinha é "preciso romper a casca do ovo", nesse sentido ele alerta que a "ordem presente apresenta-se como algo harmoniosamente 
coordenado, estavelmente coordenado; e a multidão dos cidadãos hesita e se assusta na incerteza que poderia resultar uma mudança radical” (GRAMSCI, 2004, p. 77).

Comte (2000) desconsidera a necessidade de uma revolução, de uma transformação basilar, afirmando que só a filosofia positiva pode pôr fim à crise e sustentar uma organização social que vise o progresso. Carente de subsídios para se afirmar como teoria social, o conservadorismo se apoiou no positivismo para se legitimar cientificamente, com foco na produção de conhecimento que sustente a ordem burguesa, na perspectiva de regulação das crises do sistema capitalista.

Nesse sentido a obra de Durkheim incorporou forma muito incisiva os elementos fundantes do conservadorismo na tentativa de evitar uma revolução de cunho socialista, coibindo o que ele denomina de anomia, buscando construir laços solidários entre os indivíduos para que a sociedade burguesa não se dissolva (ESCORSIM NETTO, 2011).

Esses elementos centrais do conservadorismo, problematizados por Durkheim, se firmam no ideário de cientificidade como único caminho para construção de um conhecimento seguro capaz de responder aos problemas sociais. Propostas de reformas são entendidas como solução para a manutenção da ordem social, principalmente aquelas de cunho moral, visto que são as mais capazes de moldar as gerações jovens em seu processo formativo. Sob o jugo das reformas que visam à ordem, a organização burguesa se mantém.

Durkheim defende a educação como elemento fundamental para a assimilação de padrões de um determinado grupo. Ao considerar a fragmentação e divisão social do trabalho e sob a ótica do positivismo funcionalista, advoga em favor de tipos diferentes de educação.

Não podemos nem devemos todos nos devotar ao mesmo gênero de vida; dependendo das nossas aptidões, temos funções diferentes a desempenhar, e é preciso está em harmonia com aquela que nos incumbe. Nem todos nós fomos feitos para refletir; são precisos homens de sensação e ação. Ao contrário, são precisos outros cujo trabalho seja de pensar. Ora o pensamento só pode se desenvolver ao se desprender do movimento, recolhendo-se em si mesmo e desviando o sujeito da ação exterior para que ele mergulhe por completo em sua mente (DURKHEIM, 2011, p. 44).

Sem esgotar o assunto, mas sob a égide do Conservadorismo clássico, podem-se elencar as seguintes premissas que o orientam: a) a autoridade e a liberdade só são legítimas quando baseadas na tradição; b) caráter restrito da liberdade; c) a democracia é perigosa; d) a laicização é danosa; e) a razão é destrutiva e não é suficiente para organizar a vida em sociedade; f) a desigualdade é natural e necessária. 
A Primeira Guerra Mundial (1914 - 1918), a Revolução Bolchevique em 1917 e as transformações sociais que se seguiram vão demarcar o fim marco inicial de um ceticismo conservador. O otimismo é transformado em angústia e desespero, o que contribui para a aproximação entre o pensamento conservador e fascismo. A partir do século XX o conservadorismo se difunde em diferentes vertentes e também se tornar objeto de conhecimento no campo da sociologia. Mannheim, Gouldner, Nisbet, a partir de perspectivas muito distintas, podem ser considerados como grandes pensadores que problematizaram o conservadorismo enquanto fenômeno sociológico.

Segundo Escorim Netto (2011), a contribuição de Mannheim sobre o conservadorismo consiste em identificar este como um estilo de pensamento. Ancorado no conceito weberiano de tipo ideal, o sociólogo classifica a ideia conservadora como um dos estilos de pensamento no bojo de ideários polarizados que emergiram após a Revolução Francesa. Para ele as diferentes formas de compreender o mundo determinam os diferentes estilos de pensamento e o ideário de defesa da ordem vigente associado ao romantismo, historicismo e rechaço ao contratualismo caracterizam o estilo conservador. Mannheim associa elementos do conservadorismo com premissas da perspectiva socialista.

Já as contribuições de Gouldner concentram-se na crítica ao conservadorismo norte-americano, personificado na obra de Parsons. Para Gouldner, o conservadorismo de Parsons é um enfrentamento diante das influências do marxismo. Trata-se de um ideário condizente com uma classe média que não se via ameaçada pelas elites do passado nem almejava um futuro diferente, desta feita, um ideário em que revolução não é vislumbrada como uma necessidade (ESCORSIM NETTO, 2011).

Escorsim Netto (2001) indica algumas proposições geria do conservadorismo segundo Nisbet, as quais podem ser identificadas como: a) a sociedade é uma entidade orgânica com leis internas e relações pessoais e institucionais sutis; b) o estado atual da sociedade não se submete a nenhuma manipulação racional e tem suas raízes firmes no passado; c) a sociedade prevalece sobre o indivíduo; d) o todo orgânico social não pode ser desmembrado; e) os fenômenos sociais são interdependentes; f) prevalece o princípio das necessidades e não dos direitos naturais; g) caráter funcionalista; h) o grupo social é a unidade irredutível da sociedade e não o indivíduo; i) valorização do sagrado, do não utilitário e do irracional; j) hierarquia é princípio para estabilidade social; k) autoridade advém de crenças e hábitos inerentes às necessidades. A mesma autora apresenta uma síntese da agenda conservadora proposta por Nisbet: afirmação da prioridade do social; 
admissão da interdependência funcional dos elementos sociais; afirmação da necessidade institucional do sagrado; valorização dos corpos intermediários; consideração da necessidade de hierarquia; preocupação com o espectro da desorganização social.

Distanciando-se da concepção de senso comum, infere-se que o ideário conservador é muito mais complexo que a mera defesa de conservação de uma forma de sociabilidade. Trata-se de um sistema de ideias, ou estilo de pensamento - fazendo uso da expressão empregada por Mannheim - que associa o ordenamento social com a valorização do sagrado, prestígio de instituições sociais já consolidadas, enaltecimento de posturas vanguardistas que privilegiam modelos hierárquicos na estrutura social entre outros elementos.

Infere-se também que não se pode adotar a ideia de um único tipo de conservadorismo, já que este possui vertente e distinções de acordo com a conjuntura social de cada período histórico. Por isso, a aproximação do ideário conservador com o fascismo se torna importante no contexto mundial, visto que os fundamentos se aproximam e, por vezes se moldam para representar um único pensamento.

O amálgama entre conservadorismo e fascismo ocorre no período pós Primeira Guerra Mundial e esteve aliado à conjuntura econômica europeia, em especial a alemã e a italiana. Segundo Fresu (2017, p. 44) o período pode ser caracterizado como "tormentos do pós-guerra", o qual ocorreu sob intensa crise "não só econômica, mas moral e, de modo geral, de civilização", as quais podem ser identificadas, de modo geral por: empobrecimento da população, desemprego em massa, degradação das condições de vida, insatisfação social e política dos grupos sociais que anteriormente detinham determinado poder econômico, político e social (pequena e média burguesia).

Essa conjuntura deu sustentação ao avanço de ideais controversos: por um lado o desenvolvimento do pensamento socialista, fortalecido pela revolução proletária ocorrida na Rússia, fato que fez surgir o receio em relação ao avanço do poder dos trabalhadores, e por outro, o fortalecimento dos ideais nacionalistas da pequena burguesia que "ambiciona estar acima das classes fundamentais em luta" e se considera "a legítima proprietária do mito de nação" (KONDER, 2009, p. 17). Tais fatos são fundamentais para o fortalecimento e ampliação do pensamento conservador e fusão com a "direita".

Em sua essência, a ideologia da direita representa sempre a existência (e as exigências) de forças sociais empenhadas em conservar determinados privilégios, isto é, em conservar um determinado sistema socioeconômico que garante o estatuto de propriedade de que tais forças são beneficiárias. Daí o conservadorismo intrínseco da direita (KONDER, 2009, p. 27). 
Enquanto acirramento do pensamento conservador que se fortalece nas condições sociais e econômicas, segundo Konder (2009, p. 53), o fascismo pode ser precisamente considerado como "uma tendência que surge na fase imperialista do capitalismo, que procura se fortalecer nas condições de implantação do capitalismo monopolista de Estado", ou seja, é "uma política favorável à crescente concentração de capital".

Ainda, o conservadorismo expresso no fascismo pode ser definido como:

[...] um movimento político de conteúdo social conservador, que se disfarça sob uma máscara "modernizadora", guiado pela ideologia de um pragmatismo radical, servindo-se de mitos irracionalistas e conciliandoos com procedimentos racionalistas formais de tipo manipulatório. O fascismo é um movimento chauvinista, antiliberal, antidemocrático, antissocialista, antioperário (KONDER, 2009, p. 53).

O contexto social e econômico da época e o conteúdo do pensamento conservador deu guarida ao avanço do fascismo na Itália e a ascensão de Benito Mussolini ao poder, o qual foi marcado por momentos de perseguição aos socialistas e trabalhadores, os quais, implícita ou explicitamente, se insurgiram contra o regime. O mesmo ocorreu na Alemanha com o fortalecimento de Adolph Hitler e o avanço do ideário nazista. Os historiadores, amplamente, já divulgaram dados e fatos do holocausto ocorrido em razão disso e as consequências, ainda não superadas, desse período.

De maneira geral e a partir das inferências teóricas apresentadas, podemos indicar algumas características do conservadorismo que ultrapassaram períodos de intensa atividade ou dormência e que agora, novamente emergem em diversas partes do globo e marcam as ações sociais e políticas no Brasil: a) nacionalismo enquanto defesa da pátria, sem que esta esteja associada à discussão de nação; b) imediatismo, fundamentado na busca de soluções imediatas para demandas sociais, políticas e econômicas; c) autoritarismo evidenciado pelo desprezo ao processo democrático e, em contrapartida, defesa de que as decisões e escolhas sejam realizadas por pessoas "notáveis"; d) xenofobismo, evidenciado no desprezo por aqueles que não se assemelham ao seu grupo, principalmente estrangeiros (mas que pode induzir o racismo); e) racismo, fundamentado na existência de raças superior e inferior; f) homofobia fundamentada na existência inconteste do gênero biológico masculino e feminino, em detrimento das discussões atuais a respeito da identidade de gênero; g) moralismo, associado aos "bons costumes"; e, por fim, f) apego à religião, em especial as de origem cristã, considerada a única vertente de crença possível e aceitável.

É importante destacar que as características acima evidenciadas se fazem presentes, em conjunto, em pequenos grupos ou de forma isolada, nas ações, na linguagem e no modo de vida de indivíduos que não aceitam que os grupos subalternos 
ocupem os espaços sociais que historicamente Ihes foram negados. Dessa forma, tais características incentivam a intolerância social, econômica, política e religiosa e põe em relevo a tolerância com a violência, o ódio e, consequentemente acirra a desigualdade social. Assim, o contexto social e econômico se torna fértil para todo tipo de exploração, ou seja, no jogo das forças materiais e produtivas, vence aquele que detém os meios de produção e, que consequentemente, exerce a hegemonia na atual sociedade capitalista, visto que é livre para comprar o que quiser.

No entanto, mesmo que a conjuntura seja desfavorável, na perspectiva materialista histórica e dialética, não se pode perder de vista a capacidade dos grupos subalternos, visto que há necessidade de formação permanente para o processo revolucionário, pois "a tarefa essencial consiste em dedicar-se de modo sistemático e paciente a formar esta força, desenvolvê-la, torná-la cada vez mais homogênea, compacta e consciente de si" (GRAMSCI, 2007, p. 46). A isso equivale afirmar que mesmo que o pensamento conservador ganhe algumas batalhas, a guerra ainda não terminou.

\section{O conservadorismo nas ações sociais e políticas}

E o senso comum é um terrível navio negreiro dos espíritos. (GRAMSCl, 2004, p. 77)

As ações sociais e políticas vinculadas ao pensamento conservador se apresentam como defensoras da ordem, visto que a contrapõem a uma possível desordem. Por isso a palavra ordem é frequentemente utilizada como positiva, enquanto seu antônimo como negativo.

Ordem e desordem são duas palavras que mais frequentemente comparecem nas polêmicas de caráter político. Partidos da ordem, homens da ordem, ordem pública... Três expressões que convergem para um único eixo, ou seja, a ordem, sobre a qual as expressões se baseiam e em tono do qual giram com maior ou menor aderência, segundo a forma histórica concreta que os homens, os partidos e o Estado assumem em suas múltiplas encarnações possíveis. (GRAMSCI, 2004, p. 76 - 77).

Sob o pretexto de garantir a ordem, o pensamento conservador contemporâneo carrega consigo traços de nacionalismo, imediatismo, autoritarismo, xenofobia, moralismo, racismo, fundamentalismo religioso entre outras propriedades. Tais traços estão presentes em ações sociais e políticas de grupos que se intitulam ou se aproximam da chamada nova direita brasileira.

Miguel (2018) vincula o pensamento conservador no Brasil ao ideário dos grupos alinhados ideologicamente a direita política. $O$ autor aponta que a direita sempre se fez 
presente no contexto brasileiro, contudo, desde a ascensão do Partido dos Trabalhadores ao posto mais alto da administração pública brasileira, essa concepção foi, gradativamente, se mostrando no cenário social e político, ganhando visibilidade e relevância. É importante destacar que o pensamento conservador procura resgatar privilégios ameaçados pelas alterações alcançadas por propostas progressistas, que têm em seu âmago o compromisso em transformar a realidade desigual e excludente na qual sobrevive a maioria da população.

Essa nova direita ganhou visibilidade com o antipetismo da segunda metade da década de 2010, mas tem suas raízes no processo de redemocratização pós período ditatorial militar. Assim, o avanço dos movimentos conservadores é abordado por Casimiro (2018) como um fenômeno construído desde os anos de 1980. Trata-se da configuração dos aparelhos privados de hegemonia, representados por segmentos de direita com viés não partidário, pelo menos de forma explícita.

Como marcos dessa direita crescente, pode-se evidenciar a criação do Instituto Liberal em 1983 e do Instituto de Estudos Empresariais (IEE) em Porto Alegre, no ano de 1894 que se constituiu numa "espécie de eixo Sudeste-Sul de difusão do pensamento conservador, responsável pela organização de um dos mais importantes eventos da agenda da direita no Brasil, o Fórum da Liberdade". Ainda, na década de 1990 ocorreu "um processo de empresariamento de funções sociais do Estado", quando diversos institutos, fundações e ONGs passaram a atuar no segmento do Terceiro Setor para a construção de um consenso político e ideológico coerente com uma visão de mundo que favorecesse os ideais do mercado (CASIMIRO, 2018, p. 42).

$\mathrm{Na}$ segunda metade dos anos 2000 "o discurso da direita passa a ganhar maior dimensão e radicalidade" (CASIMIRO, 2018, p. 43), os meios de comunicação digital, em especial as redes sociais, contribuíram para que o discurso conservador da direita avançasse. Assim, as "narrativas revisionistas e as fakenews passaram a 'redimir' determinados discursos de ódio, tidos como inaceitáveis e repulsivos por décadas pela maioria da sociedade" (CASIMIRO, 2018, p. 44).

$\mathrm{Na}$ atualidade, como uma das instituições que expressam essa nova direita, encontra-se o Movimento Brasil Livre - MBL. Nascido em 2014, atuando principalmente por meio do ciberativismo, o MBL trabalha na formação de consenso das massas, disseminando seus ideais e agregando seguidores em torno de bandeiras como anticorrupção, antipetismo, liberdade de mercado e conservação de valores cristãos e meritocratas. De maneira muito efetiva, o MBL contribuiu para a difusão do antipetismo e para a consolidação do impeachment da então presidente Dilma Rousseff em 2016. 
Por intermédio de seus intelectuais o MBL utiliza de estratégias midiáticas para cooptar as massas em torno de sua perspectiva ideológica, tendo atuação relevante na definição das eleições ocorridas no final de 2018. O resultado desse processo eletivo representou um rompimento com uma forma de governar que se estabelecia há mais de uma década e meia no Brasil e a ascensão de um grupo de extrema-direita ao poder.

Casimiro (2018, p. 45) aponta que,

Divulgando vídeos de seus membros com narrativas revisionistas e ataques aos movimentos sociais, proferindo discursos de ódio de classe e sobre minorias, criando e reproduzindo fakenews, promovendo manifestações reacionárias e viabilizando a candidatura política de seus integrantes alinhados a tradicionais partidos de direita, o MBL configura-se como uma marca dessa nova direita.

Na mesma esteira ideológica e de atuação do Movimento Brasil Livre encontramse também os movimentos Vem pra rua, NasRuas e Revoltados Online. Tais movimentos, legítimos representantes de grupos vinculados à direita e de cunho conservador têm contribuído para disseminar o ideário dualista de que existe a disputa entre o bem e o mal se caracteriza pela ação dos cidadãos de bem em defesa de um inimigo em ascensão, qual seja, o ideário de esquerda. Tal ideário, segundo o entendimento conservador, é o inimigo a ser combatido visando proteger toda a sociedade de uma possível investida comunista. Sobre o entendimento desses grupos, os quais disseminam o medo, o terror e a intolerância, destacamos Zambelli (2018, p. 96):

O regime socialista, tão adorado pela esquerda e por muitos políticos de nossa região, é a principal causa para tantas repressões. A Venezuela é um claro exemplo disso. [...]. Em nome da 'igualdade social' o ditador igualou aquela gente na extrema miséria. Não há o que comer, nem onde trabalhar. Não há saneamento básico, muito menos higiene. [...] A Venezuela é um exemplo vivo e prático para nossa época do resultado obtido para implantar o socialismo. [...]. Entretanto, na prática, o objetivo final é promover o caos e, em seguida, apresentar-se como o salvador da pátria. E é aí que o comunismo passa a dominar.

Apresentando-se como protetores da sociedade em razão da possibilidade de um caos generalizado, os grupos conservadores se apresentam como alternativa segura para manter a ordem vigente. A esse respeito Gramsci (2004) alerta que a palavra ordem se apresenta como algo fantástico, com um poder sobrenatural, visto que "a atual ordem se apresenta como algo harmoniosamente coordenado, estavelmente coordenado", incutindo medo na população em relação a qualquer alteração da realidade. Nesse sentido, "a multidão dos cidadãos hesita e se assusta diante da incerteza que poderia resultar uma mudança radical", pois o senso comum defende que "é melhor um ovo hoje do que uma galinha amanhã" (GRAMSCI, 2004, p. 77). 
Segundo Miguel (2018), o pensamento conservador presente na extrema-direita brasileira se estrutura sob três eixos: o libertarianismo, o fundamentalismo religioso e a reciclagem do antigo anticomunismo. Na ótica do libertarianismo os movimentos de direita defendem a liberdade de mercado em sua forma mais enérgica, sem nenhuma intervenção do Estado. O fundamentalismo religioso "se define pela percepção de que há uma verdade revelada que anula qualquer possibilidade de debate" (MIGUEL, 2018, p. 21), e suas principais bandeiras são oposição ao direito ao aborto, às políticas de combate a homofobia e aos modelos inclusivos de família. Na defesa de uma agenda moral conservadora os sujeitos defensores de tais propostas em geral são líderes religiosos que "desempenham o papel de novos coronéis da política brasileira" (MIGUEL, 2018, p. 21). Esses paladinos da moral cristã se propõem a lutar contra o mal representado pela esquerda, considerada por eles como comunista. Nessa linha, o anticomunismo, repaginado para o contexto atual se evidencia na interpretação fantasiosa da obra de Antonio Gramsci, denominada inconsistentemente de marxismo cultural, sob o argumento de que deve ser combatido em razão de que se caracteriza como significativo perigo aos valores conservadores da sociedade brasileira.

Segundo Almeida (2018), a ascensão global do neoconservadorismo ocorreu como resposta ao Estado de bem-estar social e à nova esquerda, pois a crise do capitalismo em meados da década de 1960 teria sido fruto do intervencionismo estatal e da crise moral desencadeada pelo abandono de valores tradicionais. Nesse sentido, a agenda neoconservadora visa restaurar a autoridade da lei, reestabelecer a ordem e implantar o Estado mínimo para fragilizar movimentos comunistas, sindicalistas, negros, feministas, etc, que pela permissividade de um Estado intervencionista e assistencialista instauraram um desordenamento societário.

O mesmo autor alerta ainda que, na perspectiva neoconservadora, democracia e cidadania podem ser ultrapassadas diante da necessidade de conservação de determinadas formas sociais. É por meio da supressão da democracia e cidadania que há possibilidade de aprovar a retirada de direitos sociais outrora conquistados e implantar políticas de austeridade necessárias para a manutenção de um modelo de sociedade. Nesse sentido, para Carapanã (2018) a nova direita se constitui como um agrupamento, em certa medida coeso, que converge elementos conservadores, libertarianos e reacionários, cujas ideias flertam com fundamentos nazistas e fascistas. Infere-se que as ações políticas e sociais empregadas pela direita conservadora são nocivas à democracia 
e mais ainda à possibilidade de uma transformação basilar na sociedade que tenham por princípios uma verdadeira emancipação humana.

O conservadorismo da atualidade está permeado por fundamentalismo religioso, meritocracia, preconceitos de classe, raça, sexo e gênero. Essa forma de pensar a realidade põe em risco a existência de grupos representativamente minoritários, favorece o estabelecimento do autoritarismo e corteja o fascismo. Nesse sentido, é urgente discutir as contradições expressas no pensamento conservador, no intuito de captar suas máximas determinações e, se possível, atuar em suas fissuras, de modo a fortalecer a luta em prol de outra forma de sociabilidade, que se edifique sob outro modo de produção e tenha o compromisso com a igualdade e justiça social.

Sob o manto das defesas conservadoras grupos sociais e políticos têm empreendido ações que disseminam a intolerância entre grupos sociais que defendem posicionamentos diferentes, impedindo o debate democrático e a convivência coletiva pacífica. No campo social, as ações conservadoras se fazem presentes nos Movimentos já indicados. No campo político, os conservadores atacam políticas e programas já instituídos que de alguma forma atendem imigrantes, negros, mulheres, homossexuais e demais grupos minoritários, sob o argumento de que tais políticas seriam estratégias esquerdistas em favor da imoralidade e da desordem social. Também se evidencia nesse contexto ações que propõem alterações no aparato jurídico normativo de modo a validar as defesas conservadoras, conforme abordado a seguir.

\section{A legislação sob a mira do conservadorismo: propostas, alterações e impactos na educação}

A educação, a cultura, ampla organização do saber e da experiência significam a independência das massas em face dos intelectuais (GRAMSCI, 2004, p. 212).

$\mathrm{O}$ avanço do conservadorismo no Brasil no século XXI reflete o processo histórico social, político e econômico do país, mostrando resultados de sua formação cultural, dos avanços e recuos ocorridos sob a batuta de governos militares no período republicano e, ainda das determinações de classe expressas no desenvolvimento capitalista. Por isso, o conservadorismo brasileiro evidenciado na ascensão da direita não é algo totalmente novo, mas encontrava-se adormecido, amedrontado ou inerte e, em razão da crise política encontrou as condições objetivas necessárias para se mostrar e se fortalecer, 
principalmente sob alguns argumentos que encontraram receptividade no senso comum e, de certa forma, age em busca do consenso da sociedade em torno de seus pressupostos.

Nas sociedades modernas, regidas por um aparato legal e normativo que exerce a função de coibir ações e definir modos de agir, a elaboração legislativa se torna central, visto que as leis impulsionam a coletividade para o respeito aos seus dispositivos, sob a utopia de que tais instrumentos legais indicam a vontade coletiva. A esse respeito Gramsci (2004, p. 248) alerta que,

É opinião muito difundida, ou melhor, é opinião considerada realista e inteligente que as leis devem ser antecedidas pelo costume, que a lei só é eficaz quando ratifica os costumes. Esta opinião está contra a história real do desenvolvimento do direito, que sempre exigiu uma luta para se afirmar, luta que, na realidade, é pela criação de um novo costume.

Nessa perspectiva, o direito, sustentado pelas leis, intervém na vida dos cidadãos sob a justificativa de manter a ordem social. Desse modo, as leis são elaboradas sob a lógica da democracia burguesa, ou seja, por um grupo social que exerce o domínio político, sustentado pelo domínio econômico. Tais grupos impõem à sociedade "aquelas normas de conduta que estão ligadas à sua razão de ser e ao seu desenvolvimento" (GRAMSCI, 2004, p. 249). Por isso, as leis, que são propostas em razão de interesses de determinados grupos, se tornam tão importantes para a manutenção da hegemonia.

A capacidade máxima do legislador pode se deduzir do fato de que, à perfeita elaboração das diretrizes, corresponde uma perfeita predisposição dos organismos de execução e de controle e uma perfeita preparação do consenso "espontâneo" das massas, que devem "viver" aquelas diretrizes, modificando seus hábitos, sua vontade e suas convicções de acordo com aquelas diretrizes e com os objetivos que elas se propõem corrigir. (GRAMSCI, 2004, 302)

Para conseguir controle e o consenso e, ainda, alterar o modo de vida, as leis podem indicar mudança de hábitos, interferir na vontade e convicções dos indivíduos, visto que, elaboradas sob a lógica da representatividade que rege a democracia parlamentar, são vistas como expressão do pensamento da maioria. Assim, a legislação educacional, por interferir diretamente na organização curricular e oferta da educação, interfere sobremaneira na formação das novas gerações. Nesse ponto, conforme vinculação com interesses conservadores ou progressistas, a legislação demonstra toda sua força para interferir na ordem social.

No caso brasileiro, as investidas conservadoras no campo educacional têm se acirrado, principalmente com a ampliação da bancada parlamentar comprometida com os interesses dos grandes proprietários, dos grupos que visam criminalizar ações com 
justificativas de purificar a sociedade e, consequentemente com a perspectiva divina, expressa na defesa da religião e da família.

Os parlamentares que representam os grandes proprietários não são figuras novas na política brasileira, visto que a história tupiniquim amplamente já demonstrou o poder exercido pelos "Coronéis". No entanto, com a abertura política pós período ditatorial e o processo de globalização iniciado na última década do século XX caracterizado pela abertura alfandegária e fiscal para produtos estrangeiros e a investida do capital internacional no mercado nacional, esses grupos assumem também a representatividade dos grandes empresários, nacionais e internacionais.

A franca ascensão de novos grupos políticos (principalmente aqueles ligados à defesa da bíblia - pastores e leigos ligados a diversas correntes cristãs, e aqueles que têm discurso de resolver os problemas da criminalidade) pode ser associada às necessidades sociais. Os primeiros conseguem ascensão na receptividade dos grupos subalternos, que sob os efeitos da exploração buscam alento no divino. A esse respeito, Marx já alertou em 1843 que "[...]. A religião é o suspiro da criatura oprimida, o ânimo de um mundo sem coração, assim como o espírito de estados de coisas embrutecidas. Ela é o ópio do povo." (MARX, 2010, p. 145). Sob o estigma do divino e da possibilidade de alento para as necessidades físicas e do espírito, os parlamentares desse grupo encontram apoio em parte significativa da população. O apoio para a ascensão do segundo grupo se fundamentou no receio da população em relação ao avanço da criminalidade no país, fato amplamente divulgado pela mídia sem debate a respeito da emergência de políticas públicas de enfrentamento à desigualdade social, e de educação e segurança. Esse grupo é representado por parlamentares oriundos ou com aproximação dos aparelhos repressivos do Estado, tais como polícia e forças armadas. Podemos inferir aproximação com o pensamento gramsciano sobre o cesarismo, quando o autor alerta que a transformação do aparato policial em sentido amplo pode se caracterizar "[...] não só do serviço estatal destinado à repressão da criminalidade, mas também do conjunto das forças organizadas pelo Estado e pelos particulares para defender o domínio político e econômico das classes dirigentes" (GRAMSCI, 2007, p. 78).

Os grupos de parlamentares mencionados influenciam cada vez mais as demandas do poder legislativo, seja municipal, estadual ou Congresso Nacional, visto que alçaram número significativo de cadeiras nas respectivas casas legislativas. Essa influência reflete em ações, Projetos de Lei e Leis que expressam o ideário que os conduziu ao Parlamento. 
No campo da educação, inúmeros Projetos de Lei tramitaram ou tramitam nas diversas casas legislativas do país, evidenciando a ação de grupos conservadores que pretendem impor determinado modo de vida e de pensamento. De modo a evidenciar o poder de determinados grupos, algumas características conservadoras se fazem mais presentes que outras em tais propostas. Para exemplificar a questão destacamos as seguintes situações:

1. A discussão em torno das questões relativas à orientação sexual, identidade e ideologia de gênero, colocadas em pauta entre 2014 e 2015, quando ocorreu a elaboração dos Planos Estaduais e Municipais de Educação em todo o País: em diversos estados e municípios, por força da pressão de grupos conservadores, as estratégias propostas sobre a questão foram suprimidas ou alteradas no texto final transformado em Lei. Com mesmo teor de desvalorizar as discussões relativas à orientação sexual e identidade de gênero tramita na Câmara dos Deputados o PL 1239/2019, que visa proibir a aplicação de recursos públicos, bem como o uso das estruturas e instituições da Administração Pública Direta ou Indireta, das Fundações, Autarquias e Empresas Públicas e Privadas prestadoras de serviços do Governo Federal, Estadual, Distrital e Municipal e outros, em ações sobre a questão.

2. A obrigatoriedade da exposição, leitura e distribuição de exemplares da bíblia em escolas tem sido foco de proposições em diversos estados e municípios, culminando com a aprovação de Leis de abrangência local ${ }^{6}$. Sobre a questão o Poder Judiciário, quando provocado, tem decidido pela inconstitucionalidade das propostas. Em âmbito nacional tramitam propostas de alteração da Lei de Diretrizes e Bases da Educação Nacional - Lei 9394/96, com vistas a instituir a obrigatoriedade da leitura e o ensino da bíblia nos currículos de escolas de ensino fundamental e médio ${ }^{7}$.

3. Sob a insígnia de proteção de interesses familiares, proteção dos alunos da ideologia "nociva" pregada por professores e de uma formação neutra, são quase incontáveis as propostas de leis municipais e estaduais que pretendem instituir uma "Escola sem Partido". Em âmbito nacional, inúmeros projetos de Lei a denominação de "Escola

\footnotetext{
${ }^{6}$ Para exemplificar a questão, citamos os seguintes casos: Em Goiás, tramita o Projeto de Lei № 788/2018, indicando a leitura de textos bíblicos em escolas públicas e privadas. A Lei Estadual 5.998/2011 - RJ, declarada inconstitucional pelo TJ-RJ, obrigava as escolas públicas e privadas a terem em sua biblioteca um exemplar da Bíblia. A Lei no 9734/2015 do município de Florianópolis, também declarada inconstitucional, obrigava a disponibilização de bíblia na escola e autorizava sua distribuição na semana que antecede o Dia do Livro. Várias propostas de mesmo teor tramitam em todo o país e destacamos que a maioria delas é de autoria de parlamentares vinculados às Igrejas Evangélicas e Pentecostais.

7 Sobre a questão destaca-se o PL 943/2015, que a inclusão do ensino da Bíblia nos ensinos fundamental e médio da educação básica e o PL 9164/207, que propõe o ensino da bíblia como disciplina obrigatória no currículo do ensino fundamental e médio.
} 
sem Partido" tramitam no Congresso Nacional ${ }^{8}$, os quais encontram receptividade em parlamentares das duas casas legislativas.

4. A restrição de recursos na educação pública interfere no padrão de qualidade da educação oferecida à população e dá guarida às propostas de desobrigação do Estado com a oferta educacional, sob o pretexto de autorização de oferta de educação domiciliar ("homeschooling"), conforme proposto no Projeto de Lei 490/2017, que tramita no Senado Federal. Proposições dessa natureza expõem, reafirmam e naturalizam a divisão social e a consequente desigualdade por ela gerada e, ainda, desqualifica o trabalho formativo realizado pela escola.

5. Sob a justificativa de manutenção e garantia da ordem pública tem crescido as propostas de militarização de escolas, de forma a repassar a gestão de unidades escolares para a responsabilidade da polícia militar ${ }^{9}$. Tais propostas encontram adesão na sociedade em razão da preocupação com a segurança e o avanço da violência no país, além da defesa de forma[ta]ção do jovem à um modelo de disciplina e obediência, típicos da esfera militar.

A aprovação das propostas supracitadas, ou de propostas semelhantes, indica como o pensamento conservador se faz presente na ação dos sujeitos que o defendem e como encontram adesão na sociedade como um todo. É importante destacar que a implementação de tais propostas pode ou não encontrar resistência, a depender dos locais em que serão implementadas, da cultura e dos sujeitos envolvidos. No entanto, por menor que seja o apoio social, ao serem implementadas no campo educacional impactam sobremaneira na formação do pensamento dos jovens impedindo a apreensão das contradições expressas no real, e, consequentemente, inviabilizando a compreensão da realidade. Isso quer dizer que os impactos de tais propostas na educação interferem na possibilidade de enfrentamento das desigualdades, colabora para a subserviência dos interesses hegemônicos e torna débil a ação de grupos subalternos.

De modo geral, as propostas conservadoras evidenciadas nos Projetos de Lei e nas Leis já aprovadas incitam a intolerância com as minorias; a pregação de um caminho

\footnotetext{
8 Na Câmara dos Deputados, destaca-se a tramitação do Projeto de Lei 7180/2014, ao qual estão apensados os seguintes Projetos com mesmo teor, ou questões semelhantes: PL 7181/2014, PL 867/2015, PL 246/2019PL 1859/2015, PL 5487/2016, PL 10577/2018, PL 10659/2018, PL 8933/2017, PL 9957/2018, PL 10997/2018; PL 258/2019; PL 375/2019.

9 No Estado de Goiás inúmeras Escolas Estaduais têm sido transformadas em unidades de Colégios Militares. No Distrito Federal em 2019 a Secretaria de Estado de Educação e a Secretaria de Estado de Segurança Pública emitiram a Portaria Conjunta ํㅡ 01/2019 de forma a instituir a Gestão Compartilhada entre os dois órgãos nas escolas públicas. Avançam no Brasil iniciativas da mesma natureza em vários municípios e estados.
} 
possível, qual seja, o da naturalização da desigualdade de classe; a perseguição e criminalização de profissionais da educação; a interferência doutrinária religiosa na organização curricular em detrimento dos conhecimentos científicos historicamente produzidos pela humanidade; a redução de investimento público na educação e consequente desobrigação do Estado com a oferta de educação de qualidade; a imposição de uma disciplina e ordem pautada na subserviência, além de outras questões que reduzem o poder da educação escolar sobre a formação das novas gerações e impedem a vivência de processos democráticos.

Por todas essas questões o avanço do pensamento conservador precisa ser analisado e combatido, visto que possíveis retrocessos poderão não ser revertidos em curto e médio prazo.

\section{Considerações finais}

As investidas conservadoras na atualidade que se expressam na legislação vigente e nos Projetos de Lei em processo de tramitação são uma ameaça à democracia burguesa e um entrave na construção de um projeto de sociedade que vise a formação humana e não interesses mercantis.

Primeiramente o conservadorismo é uma ameaça à democracia, em razão de que flerta com o fascismo, partindo de uma concepção higienista onde o mal deve ser expurgado da sociedade, abrindo margem para inúmeras atrocidades em nome da moral e de determinados costumes. Em segundo lugar, no campo da educação, a empreitada conservadora, obcecada no ataque às questões culturais, reduzem significativamente as possibilidades de acesso aos conhecimentos historicamente produzidos, imprescindíveis ao desvelamento do real. Dessa forma, as ações conservadoras agem para apaziguar a luta de classes, naturalizando as desigualdades, a intolerância e os conflitos inerentes à sociedade capitalista, de forma a impedir a possibilidade de enfrentamento da realidade e a busca de um ordenamento societário justo e igualitário.

Entendemos que uma concepção de mundo que exalta princípios como nacionalismo, imediatismo, autoritarismo, xenofobia, moralismo, racismo, fundamentalismo religioso, entre outros, deve ser amplamente combatida sob o risco de retrocessos caríssimos à história da humanidade.

Para além de uma forma de pensar a sociedade, o conservadorismo se materializa em ações concretas que trazem prejuízos a todos aqueles que de alguma forma se põe como subversivos a ordem vigente. Os chamados comunistas - categoria que no senso 
comum da direita brasileira abarca qualquer movimento que confronte algum ideal basilar do pensamento conservador - os negros, os LGBTI+, as mulheres, as feministas, os quilombolas, os indígenas e diversas outras minorias representativas estão sob ataque e forte ameaça dos conservadores. Tais ataques e ameaças vilipendiam não apenas suas ideologias, mas também suas vidas.

Por isso, é urgente compreender, problematizar e enfrentar o pensamento conservador nas mais diversas áreas e principalmente na educação, visto que seu avanço limita a formação dos estudantes e o trabalho dos professores, fatos que colaboram para a naturalização de uma sociedade desigual, preconceituosa e subserviente aos interesses dominantes.

\section{REFERÊNCIAS}

BURKE, E. Reflexões sobre a revolução na França. Tradução José Miguel Nanni Soares. São Paulo: Edipro, 2014.

CASIMIRO, F. H. C. As classes dominantes e a nova direita no Brasil contemporâneo. In: GALLEGO, E. S. O ódio como política: a reinvenção das direitas no Brasil. São Paulo: Boitempo, 2018. p. 41 - 45.

COMTE, A. Curso de filosofia positiva. São Paulo: Nova Cultural, 2000.

DURKHEIM, E. Educação e Sociedade. Petrópolis: Vozes, 2011.

ESCORSIN NETTO, L. O conservadorismo clássico: elementos de caracterização e crítica. São Paulo: Cortez, 2011.

FRESU, G. Nas trincheiras do ocidente: lições sobre fascismo e antifascismo. Ponta Grossa; UEPG, 2017.

GRAMSCI, A. Cadernos do Cárcere. v. 3. Rio de Janeiro: Civilização Brasileira, 2004. p

GRAMSCI, A. Antes de tudo, precisamos ser livres. GRAMSCI, A. Escritos Políticos. v. 1. Rio de Janeiro: Civilização Brasileira, 2004. p. 211- 213.

GRAMSCI, A. Três Princípios, Três Ordens. In: GRAMSCI, A. Escritos Políticos. v. 1. Rio de Janeiro: Civilização Brasileira, 2004. p. 76 - 84.

KONDER, L. Introdução ao fascismo. 2 ed. São Paulo: Expressão Popular, 2009.

MARX, K. Crítica da filosofia do direito de Hegel. São Paulo: Boitempo, 2010.

MARX, K. O Capital: crítica da economia política. Livro 1. 19 ed. Rio de Janeiro: Civilização Brasileira, 2002. 
MIGUEL, L. F. A reemergência da direita brasileira. In: GALLEGO, E. S. O ódio como política: a reinvenção das direitas no Brasil. São Paulo: Boitempo, 2018. p. $17-26$.

TOCQUEVILLE, A. de. A democracia na América. São Paulo: Editora da Universidade de São Paulo, 2010.

ZAMBELLI, C. Não foi golpe: os bastidores da luta nas ruas pelo impeachment de Dilma. Rio de Janeiro, LVM, 2018. 